\title{
PENGARUH ORGANIZATIONAL CITIZENSHIP BEHAVIOUR (OCB) TERHADAP KINERJA KARYAWAN (Studi Pada PT. Urchindize Cabang Madura)
}

\section{THE EFFECT OF ORGANIZATIONAL CITIZENSHIP BEHAVIOUR (OCB) TOWARD EMPLOYEE PERFORMANCE (A Study at PT. Urchindize Madura Branch)}

\author{
Unsul Abrar \\ Universitas Wiraraja \\ E-mail: unsulabrar@wiraraja.ac.id \\ Isyanto \\ Universitas Wiraraja \\ E-mail: isyanto85@wiraraja.ac.id
}

\begin{abstract}
ABSTRAK
Organisasi laba atau dalam hal ini adalah perusahaan yang berkecimpung dalam dunia bisnis perlu untuk selalu mengevaluasi diri untuk bagaimana bertahan dalam persaingan yang sangat kompettitf tersebut serta dituntut untuk selalu melakukan perubahan atau pembenahan untuk kelangsungan dan perkembangan organisasi yang lebih efektif dan efisien. Oleh karenanya Perusahaan harus mampu dan bisa mempertahankan kinerja perusahaan ataupun perusahaan secara keseluruhan dan dapat mengembangkan ataupun meningkatkan kinerja pada setiap karyawan, perilaku OCB adalah merupakan kinerja yang diharapkan mampu merubah fenomena yang terjadi di dunia kerja dengan mengedepankan saling memahami dan toleransi yang tinggi antar karyawan, adapun populasi yang menjadi objek penelitian ini adalah PT.Urchindize Indonesia Madura yang selama ini bergerak di bidang perikanan. Data penelitian diperoleh dari beberapa kuesioner yang telah disebarkan dengan teknik pengumpulan data diimplementasikan berupa pemberian beberapa pertanyaan atau pernyataan tertulis terhadap sejumlah responden untuk bisa dijawab. Skala Likert digunakan dalam mengukur beberapa kuesioner yang berupa pernyataan seseorang tentang pengaruh $O C B$ terhadap kinerja perusahaan. Hasil penelitian menyimpulkan bahwa dari beberapa indikator yang dipakai dalam penilaian tersebut bahwa nilai dari konstantanya sebesar 17,338 dan nilai koefisien dari variabel organizational citizenship behavior sebesar 0,294 serta memiliki nilai signifikan dibawah 0,05 sehingga jika variabel organizational citizenship behavior naik, maka variabel kinerja perusahaan juga akan bertambah 0,294
\end{abstract}

Kata Kunci: Organizational Citizenship Behavior (OCB), Kinerja, Sektor Jasa 


\section{ABSTRACT}

Profit organizations, in this case, are companies engaged in the business field, need to always evaluate themselves for how to survive in this highly competitive rivalry and are required to always make changes or improvements for more effective and efficient survival and development of organizations. Therefore the company must be able to maintain the performance of the company or the company itself as a whole and can develop or improve the performance of each employee. OCB is a performance that is expected to be able to change phenomena that occur in the working world by promoting mutual understanding and high tolerance among employees. The population that became the object of this research was PT.Urchindize Indonesia Madura which is engaged in fisheries. The research data was obtained from a number of questionnaires that had been distributed with data collection techniques implemented in the form of giving several questions or written statements to some respondents to be answered. Likert scale is used to measure several questionnaires in the form of a person's statement about the influence of OCB on company performance. The results of the study concluded that from several indicators used in the assessment that the value of the constant was 17,338 and the coefficient value of the organizational citizenship behavior variable was 0.294 and had a significant value below 0.05 so that if the variable organizational citizenship behavior rose, then the company's performance variable would also increase by 0.294.

Keywords: Organizational Citizenship Behavior (OCB), Performance, Service Sector

\section{PENDAHULUAN}

Perkembangan dunia bisnis pada saat ini dituntut untuk selalu bersaing dimana perusahaan harus dapat membenahi diri dalam persaingan bisnis yang semakin ketat dan sangat kompetitif maka dari fenomena dan realita diatas dapat menjadi alasan bagi perusahaan untuk selalu memperbaiki, mengembangakan, dan mengevaluasi kinerja dari karyawan perusahaan dan sumber daya manusia yang ada harus bisa menyesuaikan dengan perkembangan zaman ataupun teknologi yang semakin canggih. Organisasi laba atau dalam hal ini adalah perusahaan perlu untuk selalu mengevaluasi diri untuk bagaimana bertahan dalam persaingan tersebut serta dituntut untuk melakukan perubahan untuk kelangsungan dan perkembangan organisasi yang lebih efektif dan efisien. Oleh karena itu Perusahaan harus mampu dan bisa mempertahankan bagaimana kinerja perusahaan ataupun perusahaan secara keseluruhan dapat mengembangkan ataupun meningkatkan kinerja pasa setiap karyawan.

Kinerja perusahaan timbul baik dari segi kinerja individu ataupun kinerja kelompok. kondisi yang semakin lama semakin kompetitif ini pula dapat mengakibatkan pada munculnya persaingan antar perusahaan oleh karenanya perusahaan harus mampu menggunakan sumber daya yang dalam hal ini bisa dari segi sumber daya manusia, sumber daya material atapun modal bisa saling bersinergi satu sama lain sehingga akan mampu bersaing ditengah persaingan antar perusahaan. Persaingan yang semakin ketat pada perusahaan, menuntut perusahaan untuk memiliki SDM yang berkualitas yang dalam hal ini bisa berupa kompetensi, pengetahuan ataupun bidang keahlian tertentu bisa menjamin perusahan bisa bersaing dalam berbagai tantangan yang ada, SDM yang yang berkualitas tidak hanya pada pengetahuan ataupun skill tertentu akan tetapi dari segi yang lain bisa meningkatkan kesadaran seorang karyawan dalam menjalankan tugasnya dalam perusahan, perlu yang namanya kesinambungan aktivitas yang saling berkaitan antar karyawan dengan karyawan lainnya demi lancarnya masing-masing tugas karyawan dan demi terpeliharanya keyamanan ataupun toleransi antar karyawan. 
Kesadaran berupa toleransi ataupun saling memahami dalam berinteraksi di dunia kerja sangatlah dibutuhkan, perilaku kewargaan atau yang lebih popular disebut organizational citizenship behavior merupakan salah satu solusi bagaimana meningkatkan kesadaran antar karyawan dan bisa menjadi keterlibatan karyawan pada tugas karyawan lainnya demi tercapainya suatu kinerja yang baik.

Menurut Robbins (2008:31) Organizational Citizenship Behavior (OCB) adalah perilaku yang dilakukan oleh seorang karyawan yang melebihi kewajiban kerja formal,namun berdampak baik karena mendukung efektivitas organisasi. sehingga kinerja perusahaan dapat memberikan kinerja yang meningkat serta toleransi yang telah dipraktekkan nantinya dapat memberikan budaya yang cukup baik bagi perusahaan ataupun organisasi. OCB sangatlah menarik untuk diteliti karena berbagai hal yang menjadi dimensi atau unsur-unsur keterkaitan dengan saling mempengaruhi antar kinerja perusahaan dalam merealisasikan OCB tersebut, maka peneliti tertarik untuk meneliti lebih lanjut bagaimana perkembangan dan perubahan yang terjadi setelah aktivitas ataupun beberapa perilaku yang menunjukan OCB dan bagaimana pengaruhnya atau dampaknya pada kinerja perusahaan atau perusahaan.

\section{TINJAUAN PUSTAKA}

\section{Organizational Citizenship Behavior (OCB)}

Robbins (2015:19) menyatakan perilaku kewargaan (citizenship behaviour) merupakan perilaku diskresioner yang berkontribusi pada lingkungan psikologis dan social di tempat kerja. Jadi organisasi ataupun perusahaan yang sukses adalah membutuhkan pekerja yang mampu malakukan lebih dari sekedar tanggung jawab biasa tapi bagaimana mampu menciptakan kinerja yang diatas harapan.

Kinerja yang baik akan mempengaruhi budaya organisasi, sehingga budaya organisasi sangat dipengaruhi oleh OCB sebagaimana dijelaskan Kusdi (2011:111) bahwa Organizational Citizenship Behavior (OCB) dapat tercipta salah satunya melaui budaya organisasi. Sedangkan Budaya organisasi yang baik akan menambahkan nilai positif bagi kelancaran kinerja organisasi (Luthans dalam Riani, 2011:8).

Terkait dengan indikator maupun dimensi Organizational Citizenship Behavior Menurut Organ dalam (Ramadhan:162 ) bahwa terdapat 5 dimensi yang mendasari terjadinya perilaku Organizational Citizenship Behavior (OCB) pada karyawan perusahaan, yaitu Altruism, Conscientiousness, Sportmanship, Courtessy, dan Civic Virtue. Wirawan (2013: 723) menjelaskan hal tersebut. Perilaku OCB memiliki pengaruh terhadap peningkatan kuantitas bahkan kualitas produktifitas individu pegawai yang pada gilirannya akan mempengaruhi peningkatan kinerja organisasi.

\section{Kinerja Karyawan}

Pegawai maupun karyawan pada umumnya akan bekerja pada standar tertentu yang telah menjadi aturan bersama akan tetapi pada perspektif berbeda jika OCB dapat ditingkatkan mampu menjadi budaya yang baik dalam perusahaan maka akan memberikan sumbangsih ataupun peningkatan yang lebih baik pada kinerja perusahaan yang pada akhirnya akan berdampak terhadap peningkatan kinerja perusahaan. Rue dan Byars (1980) mendefinisikan kinerja sebagai level pencapaian suatu aktivitas.

Mangkunegara (2011:97), mengatakan bahwa istilah kinerja berasal dari kata "job performance"atau "actual performance" yaitu unjuk kerja atau prestasi sesungguhnya yang dicapai oleh seseorang dalam melaksanakan tugas sesuai dengan tanggung jawab yang diberikan kepadanya. Sedangkan definisi kinerja menurut Hasibuan (2011 : 94) Kinerja adalah suatu hasil yang dicapai seseorang dalam melaksakan tugas-tugasnya yang dibebankan 
kepadanya yang didasarkan atas kecakapan, pengalaman, dan kesungguhan serta waktu. Sonnentag dan Frese (2001) menyatakan bahwa kinerja indikator yang mendasar bagi kesuksesan organisasi.

Kinerja perusahaan atau perusahaan yang baik akan memberikan dampak pada kinerja sesuai dengan tanggung jawab dari masing-masing karyawan itu sendiri maka diharapkan adanya Organizational Citizenship Behaviour akan memberikan dampak postif khususnya bagi perkembangan kinerja perusahaan yang pada akhirnya akan menjadikan budaya organisasi berkembang ke arah yang lebih baik dan menjadikan organisasi atau perusahaan akan memperoleh keuntungan ataupun outcome yang menjadi dasar dari tujuan perusahaan atau organisasi dan pada perkembangan selanjutnya akan timbul feedbackyang saling menguntungkan antara organisasi dan karyawan. Adapun indikator kinerja menurut Mangkunegara (2013:51) adalah sebagai berikut :Kualitas Kerja, Kuantitas Kerja, Tanggung Jawab, Kerjasama, Inisiatif. Pengukuran atau penilaian kinerja (performance measurement) mempunyai pengertian suatu proses penilaian tentang suatu kemajuan pekerjaan terhadap tujuan dan sasaran dalam pengelolaan sumber daya manusia untuk menghasilkan barang dan jasa termasuk informasi atas efisiensi serta efektifitas tindakan dalam mencapai tujuan organisasi. (Moeheriono, 2012 : 95).

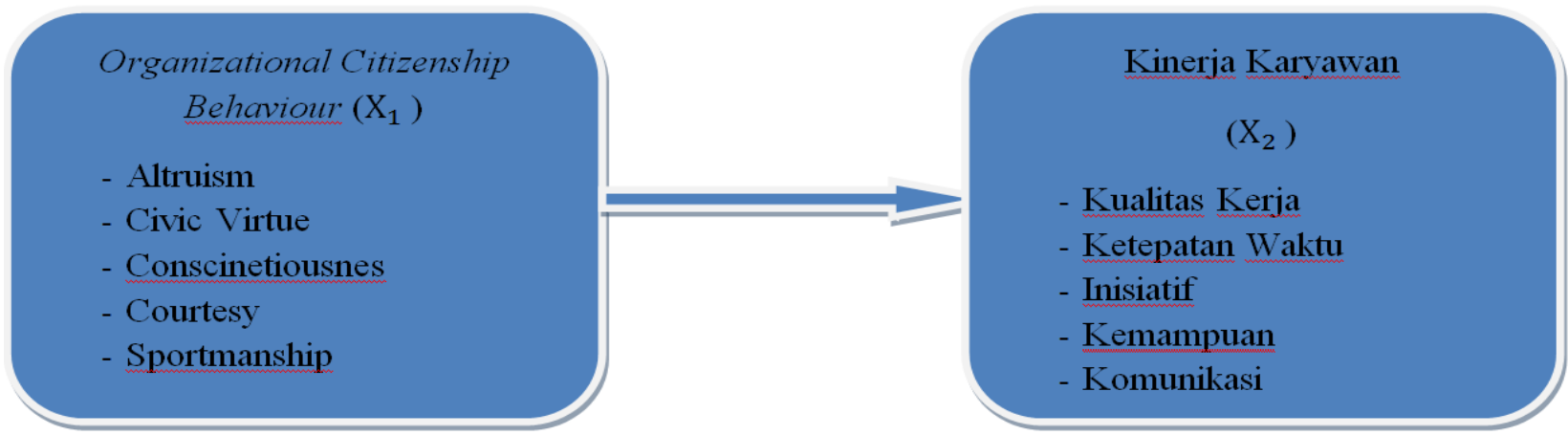

Gambar 1. Kerangka Penelitian

Sumber: Data Diolah, 2019

\section{METODE PENELITIAN}

Jenis dan pendekatan penelitian ini adalah penelitian kuantitatif dengan menekankan pada beberapa penilaian numerik atas beberapa fenomena yang dipelajari atau diteliti. Penelitian ini dilaksanakan di PT. Urchindize Indonesia Madura yang beralamat di JL. Raya Pakandangan Sangra RT 001 RW 001 Desa Pakandangan Sangra Kecamatan Bluto Kabupaten Sumenep.

Menurut sugiyono (2015:80) adalah wilayah generalisasi yang terdiri atas obyek/subyek yang kualitas dan karakteristik tertentu yang ditetapkan oleh penelititi untuk dipelajari dan kemudian ditarik kesimpulannya. Menurut sugiyono (2015: 81) Sampel adalah bagian dari jumlah dan karakteristik yang dimiliki oleh populasi tersebut.Sehingga apabila mengacu pada jumlah karyawan di PT. Urchindize Indonesia Madura yakni 196 karyawan. Teknik yang digunakan adalah proportional random sampling dimana pengambilan sampel dapat diperoleh dengan memberikan kesempatan yang sama untuk dijadikan sampel yang disesuaikan dengan proporsinya. Skala pengukuran data digunakan dalam mengukur jawaban responden dengan mengacu pada skala linkert.

Data primer merupakan data yang dapat diambil secara langsung oleh peneliti dari beberapa jawaban responden atau dari beberapa objek penelitian. Data sekunder merupakan data yang telahada pada intansi ataupun organisasi dan dikumpulkan dalam berbagai dokumen tertentu yang diluar dari peneliti sendiri 


\section{Teknik Pengumpulan Data}

Kuesioner, Yakni pengumpulan data dengan cara menyebarkan beberapa pertanyaan atau pernyataan yang sesuai dengan topik yang diteliti dengan harapan responden dapat menjawab beberapa pertanyaan tersebut. Wawancara, pengumpulan data dengan cara melakukan pertanyaan secara langsung dengan maksud agar peneliti dapat mengetahui beberapa permasalahan ataupun informasi yang berkaitan dengan topik penelitian. Observasi, Menurut Sutrisno hadi dalam (Sugiyono:145) bahwa observasi merupakan suatu proses yang kompleks, suatu proses yang tersusun dari pelbagai proses biologis dan psikologis.

\section{Uji Kualitas Data}

Uji Validitas merupakan uji ketepatan data yang terjadi di objek penelitian dengan data yang disajikan dalam penelitian ini. Uji Reliabilitas adalah sejauh mana data penelitian berupa kuesioner penelitian yang diambil dari indikator variabel penelitian dapat dipercaya \& diandalkan.

Tabel 1. Definisi Operasional Variabel Penelitian

\begin{tabular}{|c|c|c|}
\hline Variabel & Indikator & Definsi \\
\hline \multirow{5}{*}{$\begin{array}{l}\text { Organizational } \\
\text { Citizenship } \\
\text { Behaviour } \\
(\mathrm{OCB})(\mathrm{X})\end{array}$} & Altruism & $\begin{array}{l}\text { perilaku yang membantu pegawai lain dengan tanpa } \\
\text { ada paksaan yang berkaitan dengan tugas-tugas } \\
\text { pekerjaan }\end{array}$ \\
\hline & Civic Virtue & $\begin{array}{l}\text { menunjukkan aktivitas berupa ikut serta dengan } \\
\text { sukarela ataupun dukungan terhadap aktivitas } \\
\text { organisasi }\end{array}$ \\
\hline & Conscinetiousnes & $\begin{array}{l}\text { Berperan dalam dalam aktivitas ataupun tugas yang } \\
\text { melebihi standar minimum }\end{array}$ \\
\hline & Courtesy & $\begin{array}{l}\text { Ikut serta dan berpartisipasi dalam meringankan } \\
\text { terkait masalah yang berkaitan dengan pekerjaan }\end{array}$ \\
\hline & Sportmanship & $\begin{array}{l}\text { Ikut berperan serta tidak menyebarluaskan atau } \\
\text { menggunakan isu yang merusak dan pada lingkungan } \\
\text { organisasi }\end{array}$ \\
\hline \multirow[t]{5}{*}{$\begin{array}{l}\text { Kinerja } \\
\text { Karyawan (Y) }\end{array}$} & Kualitas Kerja & $\begin{array}{l}\text { Kualitas kinerja berkaitan bagaimana mengahasilkan } \\
\text { tugas dan aktivitas kerja }\end{array}$ \\
\hline & Ketepatan Waktu & $\begin{array}{l}\text { Aktivitas dan tugas kinerja yang didasarkan pada } \\
\text { ketepatan waktu yang telah menjadi standar }\end{array}$ \\
\hline & Inisiatif & $\begin{array}{l}\text { Keinginan untuk selalu mengerjakan tugas dan } \\
\text { aktivitas yang telah menjadi tugas tertentu }\end{array}$ \\
\hline & Kemampuan & $\begin{array}{l}\text { Kapabilitas karywan ataupun memberikan kemampuan } \\
\text { untuk selalu menyelesaikan tugas }\end{array}$ \\
\hline & $\begin{array}{l}\text { Komunikasi antar } \\
\text { Karyawan }\end{array}$ & $\begin{array}{l}\text { Hubungan antar karyawan dalam bentuk komunikasi } \\
\text { yang saling menghormati dan saling memahami antar } \\
\text { karyawan untuk menyelesaikan tugas }\end{array}$ \\
\hline
\end{tabular}

\section{HASIL DAN PEMBAHASAN}

\section{Hasil Uji Validitas}

Uji validitas dilakukan untuk mengetahui seberapa valid indikator yang digunakan dalam penelitian yang dimana nantinya jika nilai valid semua indikatornya, maka dapat dilanjutkan pada pengujian hipotesis. Dan dari hasil perhitungan pada tabel 2 didapatkan nilai validitas tiap 
indikator sudah memenuhi persyaratan yaitu nilainya diatas R-Tabel 0,3. Maka dapat dikatakan semua nilai indikator valid dan dapat dilanjutkan dalam pengujian lainnya.

Tabel 2. Hasil uji validitas

\begin{tabular}{cccc}
\hline Variabel & $\begin{array}{c}\text { R- } \\
\text { Tabel }\end{array}$ & $\begin{array}{c}\text { R- } \\
\text { Hitung }\end{array}$ & Keterangan \\
\hline OCB1 & 0,3 & 0,492 & Valid \\
OCB2 & 0,3 & 0,538 & Valid \\
OCB3 & 0,3 & 0,619 & Valid \\
OCB4 & 0,3 & 0,537 & Valid \\
OCB5 & 0,3 & 0,334 & Valid \\
KK1 & 0,3 & 0,355 & Valid \\
KK2 & 0,3 & 0,478 & Valid \\
KK3 & 0,3 & 0,43 & Valid \\
KK4 & 0,3 & 0,487 & Valid \\
KK5 & 0,3 & 0,539 & Valid \\
\hline
\end{tabular}

\section{Uji Reliabilitas}

Uji reliabilitas dilakukan untuk menguji keandalan dari kuisioner yang digunakan untuk mencari data, dikatakan handal jika nilai korelasinya diatas 0,6. Maka jika sudah memenuhi persyaratan dapat dilanjutkan pada pengujian selanjutnya. Dan dari hasil penelitian dilihat pada tabel 3 didapatkan nilai dari reliabilitasnya sudah diatas 0,6 setiap variabel, maka data dapat dilanjutkan pada uji selanjutnya.

Tabel 3. Hasil Uji Reliabilitas

\begin{tabular}{llll}
\hline Variabel & Korelasi & $\begin{array}{l}\text { Cronbach } \\
\text { Alpha }\end{array}$ & Keterangan \\
\hline OCB & 0,6 & 0,737 & Reliabel \\
KK & 0,6 & 0,705 & Reliabel \\
\hline
\end{tabular}

\section{Pengujian Hipotesis}

Pengujian hipotesis dilakukan untuk mengetahui suatu hubungan antar variabel organizational citizenship behavior dan variabel kinerja perusahaan. Dimana dalam melihat pengaruh antar variabelnya terletak pada kolom signifikannya, jika nilai signifikannya dibawah 0,05 maka dapat dikatakan variabel organizational citizenship behavior mempunyai dampak terhadap kinerja perusahaan. Dan pada hasil penelitian dapat dilihat dari tabel 4 nilai signifikannya organizational citizenship behavior dibawah 0,05 yang artinya memiliki dampak terhadap kinerja perusahaan.

Tabel 4. Hasil Uji Hipotesis

\begin{tabular}{|c|c|c|c|c|c|c|}
\hline \multirow{2}{*}{\multicolumn{2}{|c|}{ Model }} & \multicolumn{2}{|c|}{$\begin{array}{l}\text { Unstandardized } \\
\text { Coefficients }\end{array}$} & \multirow{2}{*}{$\begin{array}{c}\begin{array}{c}\text { Standardized } \\
\text { Coefficients }\end{array} \\
\text { Beta } \\
\end{array}$} & \multirow[t]{2}{*}{$\mathbf{T}$} & \multirow[t]{2}{*}{ Sig. } \\
\hline & & B & Std. Error & & & \\
\hline 1 & $\begin{array}{c}\text { (Constant) } \\
\text { OCB }\end{array}$ & $\begin{array}{c}17,338 \\
, 294\end{array}$ & $\begin{array}{c}1,234 \\
061\end{array}$ & 392 & $\begin{array}{c}14,052 \\
4,819\end{array}$ & $\begin{array}{l}, 000 \\
000\end{array}$ \\
\hline
\end{tabular}

Dengan model regresinya sebagai berikut :

$\mathrm{Y}=17,338+0,294 \mathrm{X}+\mathrm{e}$ 
Dapat diartikan bahwa nilai dari konstantanya sebesar 17,338 sehingga variabel OCB dainggap tetap dan tidak berubah, dan nilai koefisien dari variabel organizational citizenship behavior sebesar 0,294 serta memiliki nilai signifikan dibawah 0,05 sehingga jika variabel organizational citizenship behavior naik, maka variabel kinerja perusahaan juga akan bertambah 0,294. sehingga akan meningkatkan pula kinerja karyawan.

\section{Uji Determinasi}

Uji determinasi dilakukan untuk mengetahui seberapa besar kontribusinya variabel organizational citizenship behavior terhadap variabel kinerja perusahaan. Dan dari hasil penelitian dapat dilihat pada tabel 5 yaitu nilai $R$ squarenya 0,154 atau 15,4\%, dan sisanya dapat diketahui dalam variabel lainnya yang belum terdapat dalam penelitian ini sebesar $84,6 \%$.

Tabel 5. Hasil Uji Determinasi

\begin{tabular}{|c|c|c|c|c|c|c|c|c|c|}
\hline \multirow[t]{2}{*}{ Model } & \multirow[t]{2}{*}{$\mathbf{R}$} & \multirow{2}{*}{$\begin{array}{c}\mathbf{R} \\
\text { Square }\end{array}$} & \multirow{2}{*}{$\begin{array}{l}\text { Adjusted } \\
\text { R Square }\end{array}$} & \multirow{2}{*}{$\begin{array}{l}\text { Std. Error } \\
\text { of the } \\
\text { Estimate }\end{array}$} & \multicolumn{5}{|c|}{ Change Statistics } \\
\hline & & & & & $\begin{array}{c}\text { R } \\
\text { Square } \\
\text { Change }\end{array}$ & $\begin{array}{c}\text { F } \\
\text { Change }\end{array}$ & df1 & df2 & $\begin{array}{c}\text { Sig. F } \\
\text { Chang } \\
\text { e }\end{array}$ \\
\hline 1 &, $392^{\mathrm{a}}$ & 154 & 147 & 1,236 & 154 & 23,225 & 1 & 128 &, 000 \\
\hline
\end{tabular}

\section{Dampak Organizational Citizenship Behavior Terhadap Kinerja Perusahaan}

Jika dilihat dari hasil penelitiannya, maka organizational citizenship behavior mempunyai dampak dan berpengaruh positif terhadap terhadap kinerja perusahaan, akan tetapi dampaknya cukup kecil yaitu sekitar 15,4\%. Dikarenakan organizational citizenship behavior masih sedikit dampaknya dalam memberikan peningkatan pada kinerja perusahaan PT. Urchindize Indonesia Madura, sehingga dibutuhkan dampak lainnya selain organizational citizenship behavior dalam meningkatkan kinerja perusahaan tersebut.

Hal ini membuktikan bahwa penelitian ini relevan dengan kondisi yang terjadi di lapangan yang menjadi penelitian saat ini bahwa karyawan di PT. Urchindize Madura setuju untuk menggantikan pekerjaan sesama rekan kerja saat absen dan membantu sesama karyawan ataupun rekan kerja yang pekerjaannya dianggap overload ataupun beberapa pekerjaan yang telah menumpuk sebelumnya. Karyawan menyatakan bahwa perlu untuk saling membantu dalam meringankan beban kerja yang sangat padat tersebut demi lancarnya suatu pekerjaan dalam perusahaan. Beberapa dimensi lain dalam OCB yang memiliki relevansi di perusahaan yakni bersedia bekerjasama, menerima tugas tambahan ataupun menerima dan menyesuaikan beberapa perubahan yang terjadi dalam perusahaan. Perilaku tersebut merupakan implementasi dari beberapa dimensi OCB yang telah diakukan di Perusahaan sehingga terbentuk sebuah perilaku yang saling membantu dan memahami demi terciptanya suatu budaya yang baik dalam suatu perusahaan.

Secara teoritis pula penelitian ini diperkuat oleh Robbins dan Judge (2008:40) mengemukakan fakta yang menunjukkan bahwa organisasi yang mempunyai karyawan yang memiliki OCB (Organizational Citizenship Behavior) yang baik, akan memiliki kinerja yang lebih baik dibandingkan dari organisasi lain. jadi karyawan yang memiliki sikap OCB akan memberikan dampak yang lebih baik pada sebuah kinerja dalam suatu perusahaan.

Secara empiris penelitian ini juga relevan dengan penelitian yang dilakukan oleh Suzana (2017) yang menyatakan bahwa Organizational citizenship behavior di TASPEN Cirebon memiliki nilai rata-rata yang dapat dikategorikan baik atau tinggi mendekati interval sangat baik atau sangat tinggi, dengan persepsi karyawan yang seragam atau sama. Putri (2013) menemukan bahwa perilaku OCB pada karyawan Pamella dapat membuat kualitas kinerja karyawan Pamella 
meningkat dan terus membaik. Perilaku OCB yang sering didekatkan dengan istilah helping behavior atau dalam Islam yang dikenal attawun (tolong menolong), OCB juga merupakan konsep habbluminnas (hubungan antara manusia) yang dikenal dalam Islam penelitian ini juga membuktikan semakin tinggi atau semakin baik perilaku OCB seorang karyawan maka semakin tinggi nilai kinerja karyawan tersebut, sehingga dapat berdampak positif kepada organisasi, atau dengan kata lain karyawan Pamella sudah memiliki perilaku OCB yang baik.

\section{KESIMPULAN DAN SARAN \\ Kesimpulan}

Berdasarkan hasil analisis data yang telah dilaksanakan terhadap seluruh data yang diperoleh, maka dapat diambil kesimpulan bahwa hasil analisis regresi menggunakan uji t (Parsial) dapat dinyatakan bahwa variable organizational citizenship behavior (OCB) berpengaruh signifikan terhadap kinerja karyawan PT. Urchindize Indonesia Madura dengan dibuktikan dengan nilai signifikansi dibawah 0,05. Hasil uji determinasi sebesar $15,4 \%$ pengaruh organizational citizenship behavior terhadap kinerja karyawan sedangakn sisanya yakni $84,6 \%$ dipengaruhi oleh variabel lainnya yang belum dilakukan dalam penelitian ini seperti budaya organisasi, kualitas kerja, inisiatif, motivasi kerja, disiplin ataupun kepuasan kerja serta variable lainnya

\section{Saran}

Pihak manajemen PT. Urchindize Indonesia Madura harus lebih meningkatkan dan bagaimana mempertahankan kualitas dari OCB dan dalam hal ini dapat meningkatkan pula kinerja dari setiap karyawan, agar setiap karyawan di PT. Urchidize Indonesia Madura dapat lebih mengembangkan dan meningkatkan lagi beberapa gagasan mereka sehingga meningkatkan prestasi mereka dan kualitas kerjanya, serta dapat dibangun rasa saling menolong dan membantu meningkatkan kerja-sama dalam tim, dengan demikian kinerja karyawan di PT. Uchindize Indoensia Madura akan meningkat

\section{DAFTAR PUSTAKA}

Hasibuan, Malayu S.P. (2011). Manajemen Sumber Daya Manusia. Bumi Aksara, Jakarta.

Mangkunegara, A. (2011).Manajemen Sumber Daya Manusia. PT. Remaja Rosdakarya:Bandung

Mangkunegara, AA. Anwar Prabu (2013). Manajemen Sumber Daya Manusia. PT. Remaja Rosdakarya. Bandung.

Muheriono. 2012. Pengukuran Kinerja Berbasis Kinerja, Edisi Revisi. Jakarta: PT. Raja Grafindo Perkasa.

Putri, Alifah Rahmadiah dan Nugroho, Anton Priyo. Pengaruh Organizational Citizenship Behavior (OCB) Terhadap Kinerja Karyawan Pamella Supermarket Yogyakarta Dengan Etika Kerja Islam Sebagai Variabel Moderasi. Universitas Islam Indonesia.

Ramadhan, Fairicio Putra dkk (2018). Pengaruh Organizational Citizenship Behavior (OCB) dan good corporate governance (GCG) terhadap kinerja karyawan (studi pada karyawan PT. Taspen (persero) kantor cabang malang). Jurnal Administrasi Bisnis (JAB) Vol. 55 No. 2 Februari.

Robbins, Stephen \& Timothy A.Judge. (2008). Perilaku Organisasi, Buku 1 Cetakan, 2. Jakarta: Salemba Empat. 
Robbins, Stephen \& Timothy A.Judge. (2015). Perilaku Organisasi (Organizational Behavior). Salemba:Jakarta.

Rue, LW, LL Byars. (1980). Management: Theory and Application, Ricard D. Irwin Inc. Homewoodil.

Sonnentag , S., \& Frese, M. (2001) .Performance Concepts and Performance Theory. United Satates: John Wiley \& Sons, Ltd.

Suzana, Anna. (2017). Pengaruh Organizational Citizenship Behavior (OCB) Terhadap Kinerja Karyawan (Studi Di PT Taspen) Kantor Cabang Cirebon. Jurnal Logika, Vol XIX No 1.

Sugiyono. 2015. Metode Penelitiana Kuantitatif Kualitatif dan R\&D. Alfabeta:Bandung.

Wirawan. (2013). Kepemimpinan : Teori, Psikologi, Perilaku Organisasi, Aplikasi dan penelitian. Jakarta: Raja Grafindo Persada 